\title{
PUNTOS CLAVE SOBRE EL APGAR FAMILIAR
}

\section{KEY POINTS ON FAMILY APGAR}

\section{Federico VERA ${ }^{1}$.}

${ }^{1}$ Encargado de Cátedra de Historia de la Medicina, Facultad de Ciencias Médicas, Universidad Nacional de Asunción, filial Santa Rosa del Aguaray, Santa Rosa del Aguaray - Paraguay.

Cómo citar este artículo: Vera F. Puntos clave sobre el APGA familiar. Medicina Clínica y Social. 2018;2(2):99-101.

\section{RESUMEN}

EI APGAR Familiar, instrumento utilizado para la evaluación familiar, fue elaborado con el objetivo de que el médico de familia obtenga información de sus pacientes en relación con la situación funcional de sus familiares. Consta de cinco preguntas, aplicables a los diferentes miembros de la familia y en momentos distintos para mejor percepción de la satisfacción del entrevistado con su vida familiar. Además, es de utilidad para conocer si la familia representa una respuesta positiva para el paciente o, por el contrario, afecta a su enfermedad.

Palabras clave: APGAR familiar; funcionalidad.

\section{ABSTRACT}

The Family APGAR, an instrument used for family assessment, was developed with the objective that the family physicians obtains information about their patients in relation to the functional situation of their family members. It consists of five questions, applicable to different members of the family and at different times to better understand the respondent's satisfaction with their family life. It is also useful to know if the family represents a positive response for the patient or vice versa, it affects his/her disease.

Keywords: Family APGAR; functionality.

\section{APGAR FAMILIAR}

Es una herramienta para detectar disfunción familiar. Considerando los principios del médico de familia, el de intentar comprender el contexto de la enfermedad desde el punto de vista personal, familiar y social; se puede utilizar todas las herramientas posibles para llegar al objetivo principal de optimizar el estado de salud del paciente (1).

EI APGAR familiar se define como un instrumento cuantitativo para evaluar la percepción del paciente en relación a la situación funcional con sus familiares y nos orientara a un mejor manejo y seguimiento integral.

Para utilizarla es importante el concepto de funcionalidad familiar que es la capacidad que tiene una familia de interaccionar en forma armónica entre los componentes del mismo, donde debe premiar la comunicación, respetar las diferencias entre sus integrantes y buscar 
solucionar los problemas en forma apropiada. Por tanto, en una familia disfuncional existen situaciones conflictivas, que se caracterizan por:

- Violencia familiar

- Confusión de roles

- Dependencia excesiva

- Falta de comunicación

- Manipulación emocional

La escala utiliza cinco parámetros (Tabla 1) para determinar el grado de funcionalidad familiar (2):

- Adaptación: capacidad del individuo para adaptarse a los cambios que puedan ocurrir en situaciones de crisis.

- Participación: actividades del individuo para formar parte de las responsabilidades y toma de decisiones, confiriéndole un cierto grado de participación a cada miembro.

- Crecimiento: adquisición de una maduración física, emocional y autorrealización de cada componente de la familia.

- Afecto: constituye la relación afectiva entre los componentes de la familia

- Recursos: determinación que un individuo realiza en cuestión de tiempo, espacio y dinero con los miembros de la familia.

TABLA 1. APGAR PARA ADULTOS Y LOS PARÁMETROS UTILIZADOS

\begin{tabular}{|c|c|c|c|c|c|c|}
\hline & PREGUNTAS & $\begin{array}{l}\text { NUNCA } \\
\text { (0) }\end{array}$ & $\begin{array}{c}\text { CASI } \\
\text { NUNCA (1) }\end{array}$ & $\begin{array}{l}\text { ALGUNAS } \\
\text { VECES (2) }\end{array}$ & $\begin{array}{l}\text { CASI SIEM- } \\
\text { PRE (3) }\end{array}$ & $\begin{array}{l}\text { SIEM- } \\
\text { PRE (4) }\end{array}$ \\
\hline Adaptación & $\begin{array}{l}\text { Me satisface la ayuda que recibo } \\
\text { de mi familia cuando tengo algún } \\
\text { problema o necesidad }\end{array}$ & & & & & \\
\hline Participación & $\begin{array}{l}\text { Me satisface la forma en que to- } \\
\text { mamos las decisiones importan- } \\
\text { tes en mi familia, compartiéndola } \\
\text { entre todos }\end{array}$ & & & & & \\
\hline $\begin{array}{c}\text { Ganancia o cre- } \\
\text { cimiento }\end{array}$ & $\begin{array}{l}\text { Me satisface como mi familia } \\
\text { acepta y apoya mis deseos de em- } \\
\text { prender nuevas actividades }\end{array}$ & & & & & \\
\hline Afecto & $\begin{array}{l}\text { Me satisface como mi familia ex- } \\
\text { presa afecto y responde a mis } \\
\text { emociones como rabia, tristeza, } \\
\text { amor }\end{array}$ & & & & & \\
\hline Recursos & $\begin{array}{l}\text { Me satisface como compartimos } \\
\text { en mi familia el tiempo para estar } \\
\text { juntos, los espacios de la casa, el } \\
\text { dinero }\end{array}$ & & & & & \\
\hline $\begin{array}{l}\text { Soporte de ami- } \\
\text { gos }\end{array}$ & $\begin{array}{l}\text { Estoy satisfecho con el soporte } \\
\text { que recibo de mis amigos }\end{array}$ & & & & & \\
\hline
\end{tabular}

\section{INTERPRETACIÓN}

Se debe marcar solo una casilla en cada pregunta, con un puntaje que va de 0 a 4 puntos (0: Nunca; 1: Casi nunca; 2: Algunas veces; 3: Casi siempre; 4: Siempre) 
Al realizar la sumatoria, el puntaje va de 0 a 20 puntos; que nos indicara el nivel de disfunción del paciente en relación a su familia (2-3).

- Buena función familiar $\quad 18-20$

- Disfunción leve 17-14

- Disfunción moderada 13-10

- Disfunción severa $\quad \leq 9$

\section{CONCLUSIONES}

- No es de precisión absoluta.

- Es la percepción de satisfacción que tiene el evaluado con respecto al funcionamiento de su familia.

- El Médico de familia debe estar preparado para realizar esta encuesta y reevaluarla cuando se sospecha de una disfunción familiar.

\section{CONFLICTOS DE INTERÉS Y FUENTE DE FINANCIACIÓN}

El autor declara no poseer conflictos de interés. Fuente de financiación: ninguna.

\section{REFERENCIAS BIBLIOGRÁFICAS}

1. De Mestral E, Szwako A. Manual de Medicina Familiar. Asunción: EFACIM, 2012.

2. Suarez-Cuba M, Alcalá-Espinoza M. APGAR Familiar: una herramienta para detectar disfunción familiar. Rev Méd La Paz. 2014;20(1):53-57. URL.

3. Gómez Clavelina FJ, Ponce Rosas ER. Una nueva propuesta para la interpretación de Family APGAR (versión en español). Atención Familiar. 2010;17(4):102-106. URL. 